\title{
FRACTURE ANALYSIS OF POROUS P/M IRON BASED MATERIALS
}

\section{TEISANU Cristina ${ }^{1, a^{*}}$, GINGU Oana ${ }^{2, b}$, SIMA Gabriela², c}

\author{
${ }^{1}$ University of Craiova, Faculty of Mechanics, Dept. of ATII, 107 Calea Bucuresti, Craiova,
} Romania

\author{
${ }^{2}$ University of Craiova, Faculty of Mechanics, Dept. of IMST, 1 Calugareni, Dr.Tr.Severin, Romania \\ a cteisanu@yahoo.com, boanagingu@yahoo.com, c gsima2001@yahoo.com
}

Keywords: powder metallurgy, porous iron based materials, fracture surface, porosity, failure analysis

\begin{abstract}
Using powder metallurgy techniques new porous materials for self-lubricating bearings were developed. These materials are characterized by total porosity, which represents their major advantage for tribological applications, acting like their own oil reservoir. Sometimes the presence of pores can be also detrimental to the part performance. Among the causes of the bearings failure is their increased porosity for improving the lubricant retention capacity. Consequently, this can lead to a significant loss in strength. In the present work tensile test specimens based on $\mathrm{Fe}-\mathrm{Cu} / \mathrm{brass}-\mathrm{Sn}$ $\mathrm{Pb}$ powders were prepared in order to investigate the morphology of the fracture surfaces and to analyze the effect of pores on the failure process of these materials subjected to tensile loads. Distinct morphologies of the pores area were revealed by SEM images of the fracture surfaces.
\end{abstract}

\section{Introduction}

Controlled non-homogeneity of the structure by powder metallurgy processes makes it possible to obtain special properties of materials, which cannot be obtained by conventional technologies [1]. It is essential to know the actual loading conditions of the part and modify alloying elements and treatment parameters of the material on the basis of these conditions [2]. The porosity in sintered ferrous materials can be graded as primary porosity originating from green compacts and secondary porosity caused during the sintering process by the transient liquid phase [3]. Generally, the porosity is the most significant parameter of the $\mathrm{P} / \mathrm{M}$ products for both structural and porous part. In particular the porosity is beneficial to the sliding bearings, which decides their mechanical properties to a greater extent than any other microstructural factor (grain size, dislocation nature, texture) [4]. Due to the heterogeneity of the pores shape, size, distribution and orientation relative to the loading direction the effect of porous materials is stronger than that of non-metallic inclusions present in the structure and cause plastic deformation. Therefore, when a mechanically loaded part failed one of the main causes may be attributed to the presence of pores which influence the initiation, growth and propagation of cracks [5]. Under monotonic tensile loading, porosity in sintered microstructure reduces the effective load bearing cross-section and acts as stress concentrators for local strain and decreases both ductility and strength [6]. Usually the porosity in the sintered ferrous materials for tribological applications, such as bearings, is interconnected, as opposed to other PM engineering materials applications where porosity is relatively isolated. When the bearing is externally loaded, the interconnected porosity represents isolated sintering contacts, which leads in localization of the plastic deformation at the relatively smaller sintered regions between particles and therefore in low deformed volume [7]. In these conditions the failure of the part may occurs as a result of the applied operation loads exceeding the material strength. Thus, interconnected porosity is disadvantageous and decreases the ductility on the macroscopic level to a greater extent than isolated porosity [8]. On a macroscopic scale ductile fractures are characterized by material tearing and exhibit large plastic deformation, while brittle fractures display little or no visible plastic deformation. Since the ductility is strongly associated to the deformed volume sintered ferrous materials are in fact macroscopically brittle, even though they may behave ductile at the microscopic scale. 
The aim of the present study is to investigate the morphology of the fracture surfaces and to study the effect of pores on the failure of the sintered ferrous materials. With this aim, three compositions based on iron-copper powder and one based on iron-brass powder were prepared in order to obtain specially shaped specimen for tensile test. Qualitative analysis of the microstructure was performed in order to determine the pore size, shape and distribution relative to the sintered density and the composition of selected alloys. In addition, the pore formation and fracture surfaces of the tensile specimen were fractographic analysed using scanning electron microscopy and optical microscopy in order to correlate the observed tensile behavior with the basic fracture mechanisms.

\section{Materials and experimental procedure}

Elemental powders of $\mathrm{Fe}, \mathrm{Cu}, \mathrm{Sn}, \mathrm{Pb}$, brass and $\mathrm{MoS}_{2}$ were weighed to required proportions and mixed in a 3D homogenization device for two hours. Specially shaped specimens were produced by compaction of the powder mixtures at a pressure of $500 \mathrm{MPa}$ into a rigid die by applying pressure in a single axial direction through a rigid punch. Sintering of the compacts was carried out at a temperature of $900^{\circ} \mathrm{C}$ for 50 minutes in dry hydrogen atmosphere in order to determine the tensile strength of the PM parts in conformity with SR EN 10002-1-1995.

Reference densities for the selected compositions were calculated by the rule of mixtures and sintered densities were evaluated gravimetrically using Archimedes principle. Total porosity of the specimens was evaluated from the difference between the reference density and the measured density and investigated by microscopic analysis on polished surfaces of the sintered compacts. Fractographic examination of fracture surfaces of sintered iron based samples was performed by electronic microscopy of the shaped specimens subjected to tensile test.

The composition of the powder mixtures and experimental conditions are presented in Table 1, and densities of the sintered compacts are shown in Table 2.

The dimensions of the specimen for tensile test are presented in Fig. 1 and Table 3.

Table 1 Composition of the powder mixtures

\begin{tabular}{|l|l|l|l|l|l|l|}
\hline Alloy & $\begin{array}{l}\text { Iron } \\
{[\mathrm{wt} \%]}\end{array}$ & $\begin{array}{l}\text { Copper } \\
{[\mathrm{wt} \%]}\end{array}$ & $\begin{array}{l}\text { Tin } \\
{[\mathrm{wt} \%]}\end{array}$ & $\begin{array}{l}\text { Lead } \\
{[\mathrm{wt} \%]}\end{array}$ & $\begin{array}{l}\text { Brass } \\
{[\mathrm{wt} \%]}\end{array}$ & $\begin{array}{l}\mathrm{MoS}_{2} \\
{[\mathrm{wt} \%]}\end{array}$ \\
\hline MAS 1 & rest & 5 & 1 & 7.5 & - & 1 \\
\hline MAS 2 & rest & 5 & 1.5 & 5 & - & 1 \\
\hline MAS 3 & rest & 5 & 2.5 & 2.5 & - & 1 \\
\hline MAS 4 & rest & - & 1.5 & 5 & 5 & 1 \\
\hline \multirow{2}{*}{$\begin{array}{l}\text { Sintering } \\
\text { conditions }\end{array}$} & \multicolumn{7}{|l|}{ Sintering temperature $\left[{ }^{\circ} \mathrm{C}\right]$} & 900 & \\
\cline { 2 - 6 } & Dwell time $[$ min. $]$ & 50 & dry hydrogen \\
\cline { 2 - 6 } & Atmosphere &
\end{tabular}

Table 2 Density and porosity values of the sintered compositions

\begin{tabular}{|c|c|c|c|c|c|}
\hline \multirow{2}{*}{$\begin{array}{l}\text { Sintering } \\
\text { temperature } \\
{\left[{ }^{\circ} \mathrm{C}\right]}\end{array}$} & \multirow{2}{*}{$\begin{array}{l}\text { Dwell } \\
\text { time } \\
\text { [min] }\end{array}$} & \multicolumn{4}{|c|}{ Density $\left[\mathrm{g} / \mathrm{cm}^{3}\right] /$ Porosity [\%] } \\
\hline & & MAS 1 & MAS 2 & MAS 3 & MAS 4 \\
\hline 900 & 50 & $6.73 / 16.9$ & $6.54 / 17.4$ & $6.53 / 18.75$ & $6.09 / 23.9$ \\
\hline
\end{tabular}




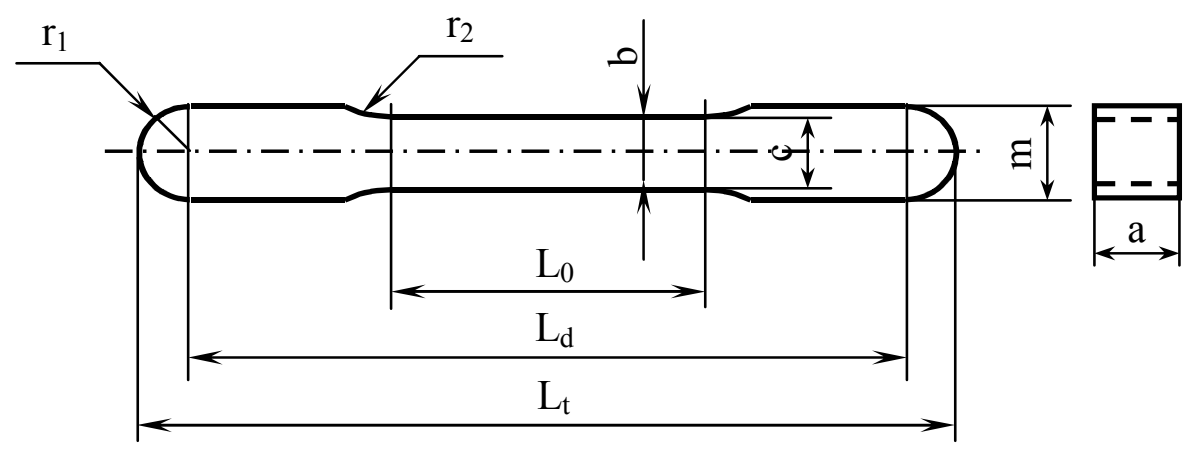

Fig. 1 Shape of the tensile test flat bar

Table 3 Dimensions of the tensile specimens [mm]

\begin{tabular}{|c|c|c|c|c|c|c|c|c|}
\hline $\mathrm{a}$ & $\mathrm{b}$ & $\mathrm{c}$ & $\mathrm{L}_{0}$ & $\mathrm{~L}_{\mathrm{d}}$ & $\mathrm{L}_{\mathrm{t}}$ & $\mathrm{m}$ & $\mathrm{r}_{1}$ & $\mathrm{r}_{2}$ \\
\hline $5,4-6$ & $5,7 \pm 0,02$ & $\mathrm{~b}+0,25$ & 32 & $81 \pm 0,5$ & $89,7 \pm 0,5$ & $8,7 \pm 0,2$ & 4,35 & 25 \\
\hline
\end{tabular}

\section{Results and discussions}

Optical micrographs of the polished and un-etched surfaces of the MAS1, MAS2, MAS3 and MAS4 compacts sintered at $900^{\circ} \mathrm{C}$ for 50 minutes show different levels of porosity (Fig. 2 and Fig. 3).

Samples made from MAS1 (Fig. 2a) show both small and large size pores with predominant irregular shape and sharp edges or needle-like shapes, and an overall non-uniform distribution, while samples made from MAS2 (Fig. 2b) present a higher degree of porosity with irregular and sharply edged pores of different sizes. Slightly more uniform distribution of the pores can be noticed, but still few much larger pores exist.
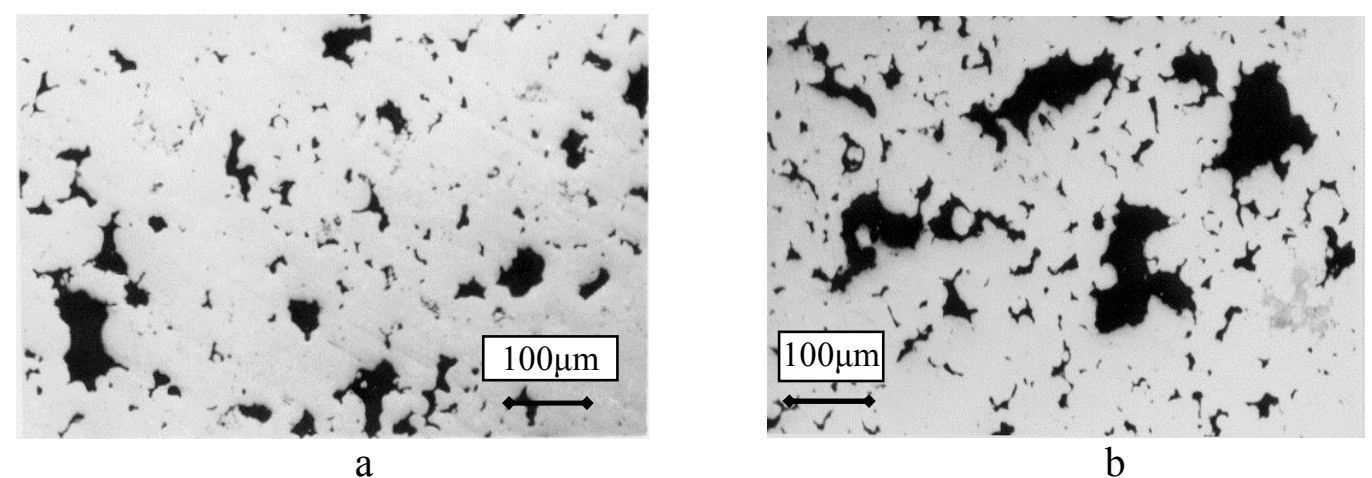

Fig.2 Micrographs showing the porosity of the MAS1 (a) and MAS2 (b) alloys

Microstructure of MAS3 sample (Fig. 3a) exhibits a much greater level of porosity with finer and smaller pores than previous microstructures. Although some agglomeration of pores still exists, the overall repartition of the pores is more homogeneous. Some large pores can be remarked, with irregular shape. Acicular and spot-like shapes, even spherical shapes, are the most predominant profiles of the pores. The above discussed microstructures correspond to samples containing copper powder and different additions of tin and lead, and reveal an increased porosity as the tin content increases, specially secondary porosity caused by the transient liquid phase of $\mathrm{Cu}-\mathrm{Sn}$.

The highest level of porosity is noticed in the sample containing brass powder, MAS4 (Fig. 3b), which is the composition with the smallest density from all materials considered for this study. Many isolated pores of different sizes and shapes, but also much more interconnected pores with irregular shapes and large sizes can be observed. It is well known that the sintering process of the components made from materials containing prealloyed powder is referred as Supersolidus Liquid 
Phase Sintering (SLPS) [9,10,11], since the prealloyed powder melts during sintering above the solidus temperature. The resulting microstructure consists of grains that were solid during sintering and a solidified liquid [12]. In this work MAS4 alloy was prepared using prealloyed brass powder. The effect of sintering at $900^{\circ} \mathrm{C}$ (temperature range for sintering of brass powder is between $815^{\circ} \mathrm{C}$ and $925^{\circ} \mathrm{C}$ ) leads to enlargement of pores and grain growth as a result of further liquid phase formation.

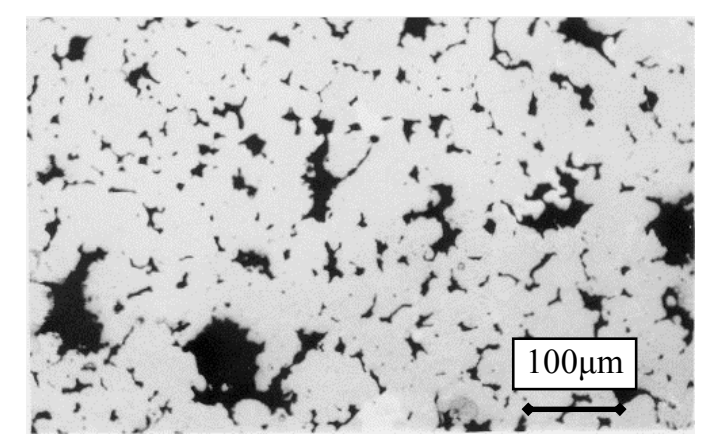

a

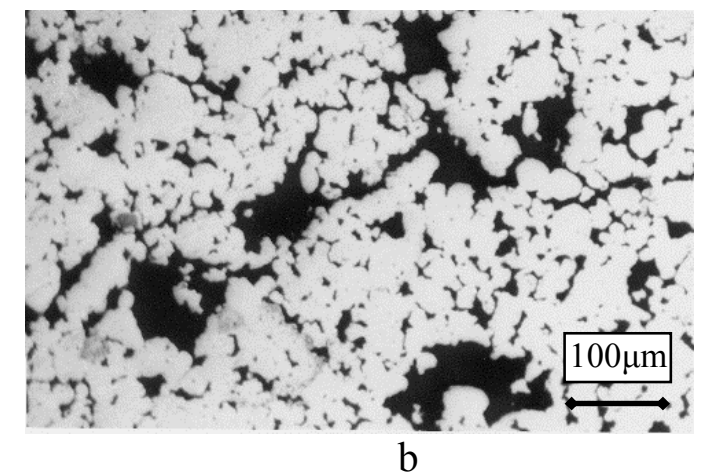

$\mathrm{b}$

Fig.3 Micrographs showing the porosity of the MAS3 (a) and MAS4 (b) alloys

When breakage of porous sintered materials occurs the fracture takes place in the area of interparticle bridges which begin to successively break due to exceeding the material strength limits. These necks act like stress concentrators and therefore their sizes and morphology influence the material strength resistance. Fracture through pores and intergranular fracture are terms often used to describe fracture paths of sintered materials. The level of the porosity affects the way the nucleation of cracks, growth and propagation of the fracture occurs. The microfractographic analysis of the fracture surfaces of the tensile loaded bars made from sintered iron-base materials considered in this study highlight the fracture area localized in the maximum porosity cross-section of the intergranular necks generated by the sintering process. Usually, plastic deformation and fracture of the sintered porous specimens occur in micro volumes through weak necks and large pores acting as stress concentrators and also in their surrounding area.

The fracture surface of the MAS1 sample (Fig. 4a) shows ductile transgranular areas with fine dimples formed by microvoid coalescence, few transgranular cleavage facets which arise by fracture of the strengthened $\mathrm{Cu}-\mathrm{Sn}$ phases. Different shape and size pores are also revealed. Isolated porosity controls the formation of different types of fracture facets related to geometry and properties of particle necks. Interface decohesion failure can also be distinguished.

On the fracture surface of the MAS2 specimen (Fig. 4b) transgranular cleavage and interface decohesion failure modes are visible, as well as inter- and transgranular ductile dimple facets with localized plastic flow.

In Fig. 5a fracture surface of the specimen made from MAS3 shows ductile areas with specific "cone-cup" features in the majority of the sintered necks. Tensile fracture first produces by localized void nucleation and growth in sintered necks of the material. The fracture surface also reveals decohesive rupture or brittle intergranular fracture which takes place without any previous plastic deformation and follows a path along grain boundaries.

The smallest quantity of the sintered neck and the largest pore size were observed in the fracture surface of the specimen containing brass powder (Fig. 5b). Ductile dimple facets with localized plastic flow occurring by fracture of the sintered necks and transgranular cleavage facets are also revealed. In this case dominantly interconnected pores control the failure by the loss of the plastic stability on the interparticle necks and by their pronounced stress concentration effect. 


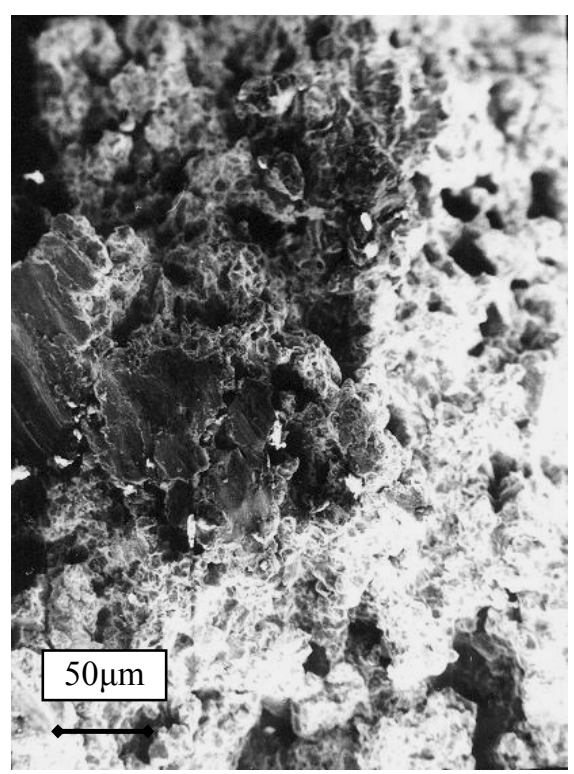

a

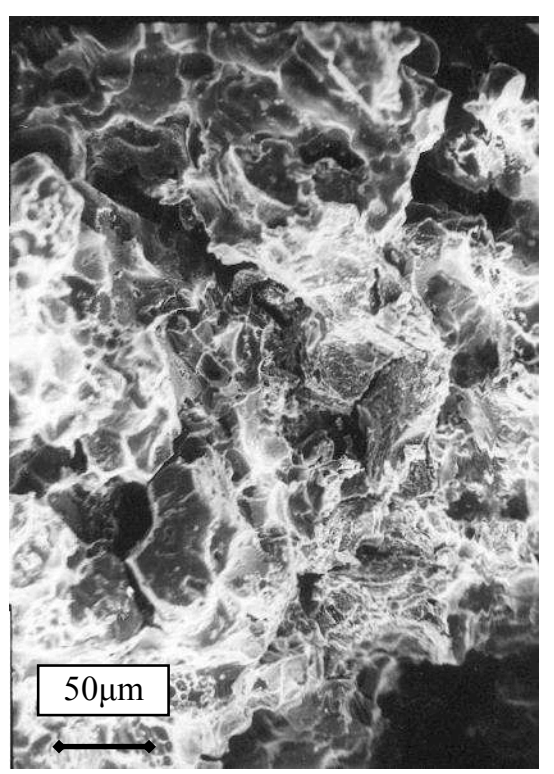

b

Fig. 4 SEM micrographs of the fracture surfaces of the MAS1 (a) and MAS2 (b) alloys

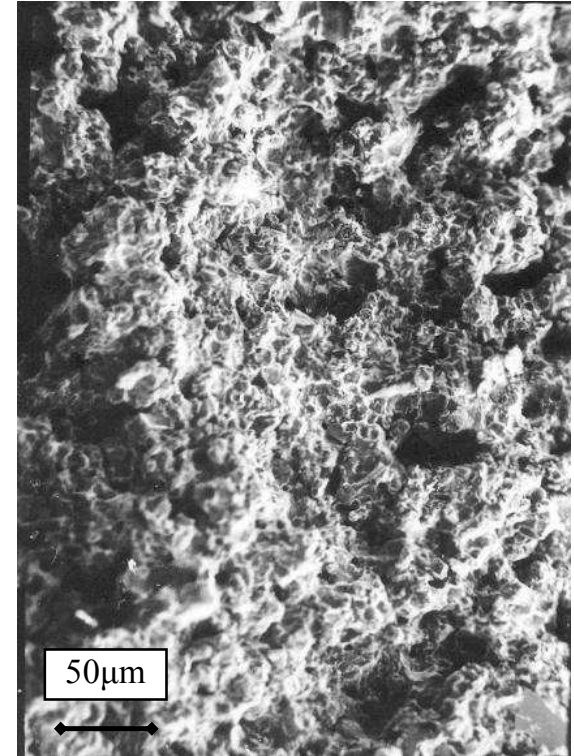

a

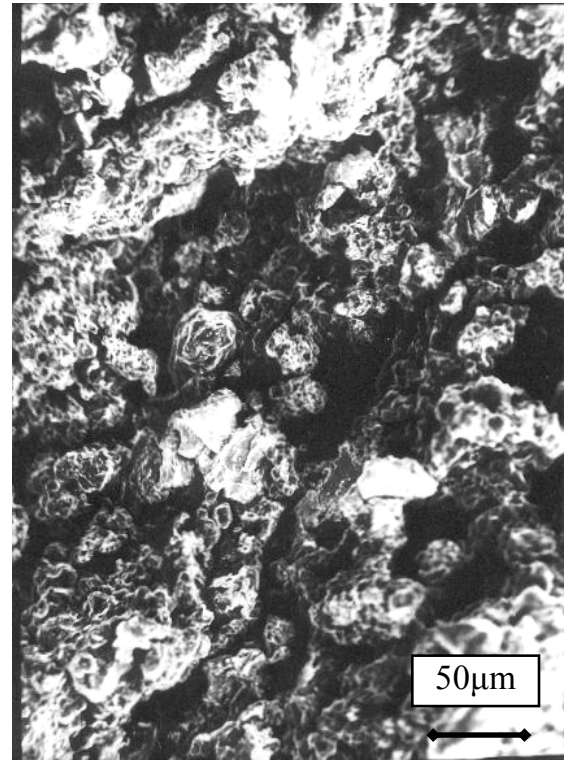

b

Fig. 5 SEM micrographs of the fracture surfaces of the MAS3 (a) and MAS4 (b) alloys

\section{Conclusions}

Analyzing the fracture surfaces of the sintered samples containing copper powder and subjected to tensile test the fracture areas are localized in the maximum porosity region of the inter-granular necks. Plastic deformation and failure of the sintered porous specimens generally occur in micro volumes with weak necks and large pores which act as stress concentrators and also in their surrounding area. Although it takes place, the fracture necking of the ductile specimens is almost invisible on the macroscopic scale because of the presence of pores in the sintered material. SEM micrographs highlight inter-particle bridges with cone-cup shape and fracture necking appears at each inter-particle bridge. In high porosity samples containing brass powder the brittle appearance of the fracture surface is denoted by the pronounced effect of the stress concentrations around pores, low plasticity and high porosity of these materials. During loading, interparticle necks deform much more extensively than the material of the particle, which results in large local plastic deformation on the microscopic scale, but in small or no visible elongation to fracture of the loaded part on the macroscopic scale. Local plastic flow of interparticle necks depends on the powder particle shape, 
pore size and the nature of the metal matrix. Therefore, the resulting fracture is ductile on microscopic scale and brittle as macroscopic appearance.

This study brings innovation and knowledge about new and advanced materials by approaching new methods to controlling the microstructure influence on the properties of greater importance for particular applications.

\section{References}

[1] A. Salak, Ferrous Powder Metallurgy, Cambridge Int. Sci. Pub., Cambridge, 1995

[2] S. Şontea et al., Metalurgia Pulberilor. Tehnologii de lucru şi aplicaţii, Ed. Universitaria, Craiova, 1999

[3] H. Danninger, Homogenization and pore formation during sintering with transient liquid phase, Powder Metall. Int., 20 (1988) 21-25.

[4] Yu.V. Mil'man, R.K. Ivashchenko, N.P. Zakharova, Mechanical properties of sintered materials. II. Effect of porosity on the ductility of sintered alloys. Soviet Powder Metall. and Metal Ceramics, 30, (1991) 250-256.

[5] E. Dudrová, M. Kabátová, Fractography of sintered iron and steels, Powder Metallurgy Progress, 8 (2008) 59-75

[6] A. Hadrboletz, B. Weiss, Fatigue Behavior of Iron Based Sintered Materials - A Review, Int. Mater. Rev., 42 (1997) 1.

[7] K.M. Vedula, R.W. Heckel, Structure-property relationships in the tensile behavior of sintered single phase ductile metals, in: H.H. Hausner, H.W. Antes, G.D. Smith (Eds), Modern Developments in Powder Metallurgy, Metal Powder Industries Federation, 1981, pp. 759

[8] N. Chawla, X. Deng, Microstructure and mechanical behavior of porous sintered steels, Materials Science and Engineering A, 390 (2005) 98-112

[9] C. Padmavathi, A. Upadhyaya, Densification, microstructure and properties of supersolidus liquid phase sintered 6711Al-SiC metal matrix composites, Sci Sinter, 42 (2011) 363.

[10] R.M. German, Supersolidus liquid-phase sintering of prealloyed powders, Metall Mater Trans A, 28 (1997) 1553.

[11] R.M. German, Supersolidus liquid phase sintering. I: Process review. Int J Powder Metall, 26 (1990) 23.

[12] A. S. Namini, M. Azadbeh, A. Mohammadzadeh, Microstructure and Densification Behavior of Liquid Phase Sintered Cu-28Zn Prealloyed Powder, Science of Sintering, 45 (2013) 351-362 